\title{
MULTIMODAL ANTHROPOLOGY AND THE POLITICS OF INVENTION
}

Ethiraj Gabriel Dattatreyan and Isaac Marrero-Guillamón

Goldsmiths, University of London

This essay and the articles included in this special issue theorize the possibilities - and pitfalls - that emerge as anthropologists utilise a combination of audio, video, text, still images, performance methodologies, and web platforms to iteratively, collaboratively, and sensually generate relations with research participants, interdisciplinary colleagues and beyond. We are not necessarily interested in developing multimedia approaches to representing or disseminating anthropological knowledge - rather, we are concerned with how multimodality may contribute to a politics of invention for the discipline. We argue that multimodality offers a line of flight for an anthropology yet to come: multi-sensorial rather than text-based, performative rather than representational, and inventive rather than descriptive. This reimagined anthropology requires a move away from established forms of authorship, representation and academic publishing towards projects that experiment with unanticipated forms, collaborations, audiences and correspondences - including questioning what the open in Open Access should signify, as Anand Pandian (2018) has compellingly argued. As importantly, a focus on multimodality and invention invites a reconsideration of the pedagogy of anthropology - both in the sense of what gets formally taught within the disciplinary canon, and in relation to the manifold ways of teaching and learning together that emerge during fieldwork, not always made visible, and which exceed the textual and conceptual domain. Indeed, we use multimodality and invention to refer to the multiple ways of doing ethnography - and the resulting multiple anthropologies - that create ways of knowing and learning together differently.

In the essay that follows we offer several provocations that multimodality and invention produce with regards to pedagogy, publication, and collaboration - which are picked up in novel ways in each of the articles included as part of this collection. Our essay is not meant as an enclosure, or a boundary, but rather a framing - that is, a point of view or an orientation to the multiple questions that emerge in each of the essays, where the respective anthropologists rethink engagement, form, and purpose in their ethnographic endeavours. We draw from John Jackson Jr. to argue that framing is at once "(1) a gesture toward contextualization (a conceptual framing of the relevant issues) and (2) a singular impression captured in time (as in the presentation of a framed painting or the relative irreducibility of a film or video still)" (2013: 485). Taking Jackson Jr.'s second point to heart, we offer this 
introductory essay as a still image by which to see with and through the ethnographic engagements of others. In this still image, the concepts of multimodality and invention are unpacked and interrogated in ways we hope offer an alternative way to think about ethnography and anthropological theory in a moment where the discipline is grappling with how to find ways to engage more effectively with the increasingly fractured and precarious worlds we inhabit.

\section{Multimodal reinventions}

We pick up the term multimodality and its (occasional) double, multisensoriality, as terms that have recently been utilised in anthropology for thinking about and with the media ecologies - i.e. the multiple media(tions) - we live in. As Collins, Durington and Gill (2017) argue in the paper that marked the birth of this section of American Anthropologist, multimodality points to the "centrality of media production in the everyday life of both anthropologists and our interlocutors," and signals the opportunities and affordances that mediating technologies have to rewire relations between anthropologists, publics, students, and research participants and colleagues in other disciplinary domains. In other words, multimodality does not only refer to an actually existing condition (the media-rich worlds we inhabit) but also to the potential the latter offer for rethinking anthropological practice. Indeed, it is multimodality's potential to reimagine the relationship between research, teaching, publishing, and public engagement (Collins et al. 2017) that we set out to explore in this collection of articles. Each of them points at a specific refunctioning of anthropology through multimodal engagements; together, they sketch the multiple reconfigurations of the discipline that an inventive engagement with multimodality makes possible. As a whole, the collection provides an image of another, multiple anthropology, creatively engaged in the task of enacting new relations, new narratives, new possibilities.

Both multiple media and senses are central to multimodality. The authors included in this special collection, however, favour a focus on the modes of encounter and address between media and subjects, rather than an emphasis on either one in and of themselves. In other words, we don't see the sensorial as distinct from the relations that emerge out of engagement. While we owe a debt to the ways in which those who have claimed and theorized the sensorial have moved us away from a text-centric approach to ethnography (e.g. Cox et al. 2016; Pink 2009; Stoller 1997), our interest in this special section is on how multimodality can offer an approach to the sensate/sensible that moves away from phenomenology (which tends to privilege a more or less unitary knowing subject, see Pink 
2011). Similarly, while we are indebted to a body of work that has reclaimed the epistemological specificity of different media (e.g. MacDougall 1998; Taylor 1996), we are more interested in identifying what these media $d o$ in our ethnographic encounters, and how they may enact the possibility of another anthropology - more public, more collaborative, more political. Multimodality, for us, points directly at a plurality of ways of doing anthropology - a plurality which is best appreciated when thought of in relation to invention.

Our use of invention primarily comes out of a genealogy that may not be the most obvious in an anthropological context (although, arguably, it constitutes something of a 'lingua franca' at Goldsmiths, University of London, the institution we both inhabit). At the center of our understanding of invention is the work of philosophers such as Gabriel Tarde, Alfred North Whitehead, Gilles Deleuze and Isabelle Stengers, later operationalized by a group of scholars coming out of Science and Technology Studies (STS) (see Marres et al. 2018). As our colleague Martin Savransky's (2016) explains, up until the $18^{\text {th }}$ Century, "invention" meant both the act of "finding out", of "discovering", as well as "fabricating" or "constructing" something. It is precisely this "pre-modern, conjunctive sense" (2016: 78) that he reclaims for the social sciences, and that we will too for multimodal anthropology. Invention, in this sense, refers to a creative, immanent mode of engagement with the subjects and objects we work with, through which unforeseeable knowledges, events and encounters may be produced. In Savransky's own work, this translates into cultivating what he calls an "alter-realism", that is, a "realism that takes the risk of asserting the reality of what is deemed improbable, implausible, marginalised, suppressed, irrelevant, even scandalous, and seeks to draw out its possible implications for the transformation of what is considered credible, reliable and serious" (2017:22).

The arguments we develop in this article also echo, expand and politicise recent work on "inventive methods" (Lury and Wakeford 2012) and "inventive social research" (Marres et al. 2018). Like these scholars, we are interested in fostering creative approaches to inquiry that participate in the performativity of social life; that indeed experiment with the what is to contribute to the what may be. Invention here signifies a commitment to creatively partake in the production of what they call "the social" - that is, the multiple relations and associations that tie people, ideas, objects, institutions, etc. together. For these authors, invention is closely related to experimentation, understood not in the narrow scientific sense, but as a form of inquiry that "attempts to purposefully deploy creative aspects of social life - including performance, materiality, reflexivity - with the aim of rendering social phenomena interpretable and knowable" (Marres et al. 2018: 18). We are interested in bringing all of 
these sensibilities around invention, experimentation, speculation into a conversation with anthropology in ways that produce inventive engagements that, rather than attempting to capture pre-existing ideas or relations through representational techniques, aspire instead to contribute to enacting new entities, new relations, new worlds. An anthropology, then, whose political character is derived from its "resistance to confining reality and being confined by it” (Marrero-Guillamón 2018a).

Arguably, there is nothing new in this provocation. Multimodal invention could be interpreted as a fanciful 21st century rearticulation of the "shared anthropology" of the not too distant past. Indeed, an excellent example of the ethics and politics of invention that precedes our current articulation is the work of Jean Rouch in West Africa in the late 1950s and 60s. Films such as Moi un Noir (1958) and Jaguar (1967) famously pioneered the use of fiction in ethnography ("ethnofiction") - opening a light of flight from the conventions of ethnographic cinema that far from derailing the possibility of doing anthropology, inventively pursued it by other means. In these films, the young men he befriended and worked with in Ivory Coast, Niger and Ghana created fictional characters and improvised the latter's lives. These characters, in turn, became powerful vehicles through which the desires, aspirations and difficulties of young migrants in (post)colonial Africa could be poetically explored. Writing about these films, Gilles Deleuze argues that Rouch's work breaks with a certain understanding of the distinction between fiction and reality - a task which is as poetic as it is political:

What is opposed to fiction is not the real; it is not the truth which is always that of the masters or colonizers; it is the story-telling function of the poor, in so far as it gives the false the power which makes it into a memory, a legend, a monster... What cinema must grasp is not the identity of a character, whether real or fictional, through his [sic] objective and subjective aspects. It is the becoming of the real character when he himself starts to 'make fiction', when he enters into 'the flagrant offence of making up legends' and so contributes to the invention of his people... He himself becomes another, when he begins to tell stories without ever being fictional. And the filmmaker for his part becomes another when there are 'interposed', in this way, real characters, who wholly replace his own fictions by their own story-telling. Both communicate in the invention of a people. (1997: 150). 
Deleuze's praise for Rouch is based in establishing a connection between invention and politics; between becoming another and inventing a people. Our goal is admittedly more humble - to reclaim for multimodal anthropology the potential that certain forms of inventive engagement may have to create an otherwise. ${ }^{i}$ Politics, in this reading, are the ways in which subjectivity in the present and for the future are co-produced by participants through performance, images, installations, interactive web platforms - towards specified goals, in some cases, and unanticipated ends in others.

Our genealogy of invention, as is probably clear by now, follows a different set of concerns than the better known (in anthropology) work of Roy Wagner, for whom invention is the crucial mechanism through which anthropologists can understand other cultures - that is, the device that allows cultures to be compared. As he puts it:

the relation that the anthropologist builds between two cultures - which, in turn, objectifies and hence "creates" those cultures for him [sic] - arises precisely from his act of "invention," his use of meanings known to him in constructing an understandable representation of his subject matter. The result is an analogy, or a set of analogies, that "translates" one group of basic meanings into the other, can be said to participate in both meaning systems at the same time in the same way that their creator does (1981, 16-17).

Wagner's theorisation of invention suggests, at least to an extent, that the relationality anthropology produced was between discrete systems of meaning and, ultimately, located in the representational works that anthropologists generated. But the implied notion of discrete cultures, which in the 1970s was taken for granted as the starting point for theorising difference, has not withstood the test of time (see, for instance, Visweswaran's [2010] historical account of the culture concept in anthropology as a stand in for racialized difference). In contrast, the kind of multimodal invention pursed in this special issue takes up an understanding of cultural meaning that is heterogeneous, fractured and dislocated. It uses this starting point, one of multiplicity, in order to displace the idea of a singular authorial account of cultural interpenetration and friction.

Wagner's assertion that invention is also central to the way cultures themselves function - indeed, invention is culture, and culture is self-invention, however, does stand the test of time and is relevant to our engagement with multimodality. Wagner's suggestion that humans must invent their culture (and that of others) as a matter of routine opens the door to 
thinking about our interlocutors as skilled theoreticians - that is, to the idea that, perhaps, we are not the ones doing the anthropologizing in the first place. Indeed, Wagner argued that it is our interlocutors, as they ascertain what is we are asking for, that do the theorising for us. This idea brings with it a powerful reversal of the anthropological gaze and forces a reevaluation of the relationship between knowing and being (epistemology and ontology) central to the discipline's self-understanding.

Wagner's work has once again come into vogue and become a generative force in recent debates around the so-called ontological turn (see Viveiros de Castro 2014). However, these conceptualizations of reversal and subsequent collaborative theorizing (see for instance De la Cadena 2015), are locked in a textual exegesis that is the anthropologists' making. Academic texts, for the most part, are the opposite of good collaborative devices: they are constructed around exclusive forms of expertise, written in an impenetrable language shared by an elite minority, and distributed in closed circuits, often behind exorbitant paywalls. The idea that text (alone) can somehow become a vehicle for capturing the complex exchanges between anthropologists and their various interlocutors as collaboration suggests that anthropology's fetishization of ethnography as text continues to dominate our modes of production and engagement (Conquergood 1988).

We are interested in how Wagner's reversal through invention can be actualized through multimodal and multisensorial engagements that radically change notions of authorship, circulation, and pedagogical relationship in and out of the "field." One of the ways in which this is already happening is the use of web 2.0 enabled (social) media that offer news ways to engage with students, research participants, and various publics about questions of mutual concern. Consider Paolo Favero and Eva Theunissen's mobile App, EthnoAlly, an interface that shares iterative data between ethnographers and participants in real time (Favero and Theunissen, 2018). This app allows participants and ethnographers to utilize the geo-mapping capabilities of the app alongside its video storage functionality to create collaborative accounts of particular phenomena, in their case of tourism in Antwerp. In this sense, anthropologists who have evoked the multimodal have gone beyond calls to engage with the digital connectivity of social media as a site of study but, rather, imagine the digital proliferation of images, texts and sound as an invitation to create and disseminate knowledge differently and with a host of others.

Multimodality has also been taken up to think more carefully about the multi-sensory worlds we co-inhabit with our interlocutors and the ways in which creative means can enliven our approach to engaging with them. Indeed, Debra Spitulnik Vidali favours the collocation 
"multisensorial anthropology" (2016) to incite a break with logocentric and positivistic models that render our co-habitation of sensory worlds with others in dull linearity. Vidali's (2016) sensuous multisensoriality is an invitation to reflexively engage with conventions of form in ethnography and to use available technologies, old and new, to depart from the monograph or the journal article as an expected endpoint. E. Patrick Johnson's one man show Sweet Tea offers one example of how the multisensorial can be enacted as ethnographic engagement. Sweet Tea provides its audiences an intimate and visceral engagement with the experiences of Gay Black men in the southern United States. It is derived from long term ethnographic fieldwork but, rather than (solely) formulated as a textual exegesis of experience (see Johnson 2011 for a written ethnography/oral history of the same title), its theatrical version engages audiences with a ventriloquation of the intimate voices of the thirteen men Johnson got to know over decades. Johnson's and Spitulnik's work suggest that new-fangled technological interventions don't necessarily comprise all that a multimodal invention could entail. However, what these performance based multimodal engagements do tell us when put into conversation with more digital technology specific interventions, is that an explicit interest in creating opportunities for collaboration are what is at the heart of multimodal invention.

\section{Inventive collaborations: the pedagogy of another anthropology}

One of the central concerns that emerges when thinking through multimodal invention are the possibilities for a more robust shared or collaborative anthropological venture. As George Marcus has argued, ethnographic practices are already taking place in a number of locales (para-sites) and conducted by unanticipated actors (para-ethnographers) so that it has ceased to be sole province of anthropologists. Marcus interprets this contemporary condition as a demand for a collaborative refunctioning of anthropology $(2008,2010)$. If our participants are already producing reflexive accounts of themselves and the world(s) they inhabit, our role necessarily must shift. As he puts it:

The basic trope of fieldwork encounter shifts from, say, apprentice, or basic learner of culture in community life, to working with subjects of various situations in mutually interested concerns and projects with issues, ideas, etc. In other words, once the "reflexive" subject is now the only kind of subject the anthropologist encounters, and where the reflexivity of the subject exists in, or overlaps with, the same intellectual universe that informs the researcher (necessarily making the subject his epistemic 
partner, so to speak, in the conduct of research), then "collaboration" replaces the trope of "apprenticeship" (or its alternatives) as defining the "scene" of fieldwork encounter. (2008: 7)

The "anthropologist as collaborator" is therefore a scholar who works with "counterparts", rather than "others", and who engages in "epistemic partnerships" (Holmes and Marcus 2008) constructed around shared concerns. This, of course, opens up a pedagogical consideration of fieldwork where learners, apprentices, and facilitators interact to articulate inquiry, a concern we will return to later in this essay. One important corollary of this (pedagogical) approach to collaboration is that the latter cannot be prefigured - and neither can its effects (Marrero-Guillamón 2018b). The question is less one of devising and implementing collaborative methodologies in order to achieve certain disciplinary goals than creating ethnographic encounters in which the very question of what is it that matters, and to whom, can be asked. Situations, in other words, in which new horizons of possibility can be imagined and enacted.

Adolfo Estalella and Tomás Sánchez-Criado’s work on “experimental collaborations” is, in this discussion, particularly relevant. They argue that conceptualising collaboration as an experimental practice opens it up to "forms of inquiry that make the forging of new anthropological problematizations possible" (2018: 7). They theorise "experimental collaboration" as one in which the "construction of problematizations is central both to the anthropologist and their field counterparts: now transformed into epistemic partners, companions sharing the endeavour of problematizing the world" (2018: 7). Reiterating Marcus's concerns of reimagining participant as counterparts, they push us to think through what it means to engage in "joint problem-making". The anthropology that results from this orientation is therefore an inventive practice, capable of constructing new questions and objects to think with. It also opens up a way to think about, as Marcus, Sánchez-Criado, and Estalella argue, questions concerning the teaching and learning of and with anthropology.

Of course, the question arises as to who can be and is most likely included in this sort of collaborative endeavour. If not interrogated, the hegemonic logics of affinity produce some as more likely collaborators and eliminate others all together. It is not so surprising, for instance, that most of the anthropological work that has focused on collaboration and counterparts on professional, elite, highly educated subjects - designers, hard scientists, and so on - as obvious interlocutors to engage in the project of "joint problem-making." These naturalized affinities to experts in other domains, while they might be fruitful in terms of the 
kinds of projects that can be endeavoured, can reproduce a logic of exclusion that limits who we might imagine as theoretical provocateurs on the grounds of gender, race, class, age or ability.

What sort of collaborations and collaborators become imaginable if we started instead from Stephano Harney and Fred Moten's (2013) theorization of "study" as speculative practice? Moten and Harney engage with the concept of study to underline a "common intellectual practice":

Study is what you do with other people. It's talking and walking around with other people, working, dancing, suffering, some irreducible convergence of all three, held under the name of speculative practice. The notion of a rehearsal-being in a kind of workshop, playing in a band, in a jam session, or old men sitting on a porch, or people working together in a factory - there are these various modes of activity. The point of calling it "study" is to mark that the incessant and irreversible intellectuality of these activities is already present. (Harney and Moten 2013: 110).

If we put the radical ecumenism of study into conversation with multimodal invention, new potentialities for who, when, how, and why we might produce work present

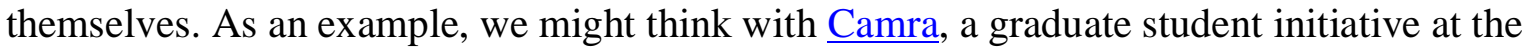
University of Pennsylvania. Gabriel, while at UPenn as a Ph.D candidate, was part of a group of graduate students supported by faculty that felt they could engage with their Philadelphia community differently and think through their scholarly projects more fulsomely if they incorporated a multimodal approach to work. While developing their respective $\mathrm{Ph} . \mathrm{D}$ projects they also engaged with projects in the greater Philadelphia area that included high school students, church congregants, and elementary school teachers (to name a few) in the process of joint-problem making. These initiatives cut across class, race, age, ability and gender by including a far broader representation of who could be counted as collaborators. These projects have since yielded films, exhibitions, and workshops as visible outputs. This possibility to quickly and effectively enact a different kind of epistemological project - one where the university becomes a resource for collective project-making - was made possible precisely because those involved with Camra began with the idea that speculative study and shared invention could be possible when engaged through a multiplicity of modalities.

In this sense, multimodal invention in anthropology brings together Marcus's redistribution (democratisation) of ethnography with a dedicated attention to the affordances 
of multimodal ethnography to produce a more inclusive possibility for who might count as collaborators. Our reimagining of invention also remixes Wagner's notion of anthropological relationality as one between abstract systems with one that is concerned with generating spaces of encounter between people and their shared concerns, interests, and questions - so that new and unforeseen ones can indeed emerge. This is not an anthropology of the here and the now, but one of the otherwise, the maybe, the possibly, the hopefully. It is also an anthropology that is invested in a multi-directional exchange of knowing and experience, a pedagogy that recognizes and takes advantage of the abundance that the reconfigured "field" - as a networked set of relations rather than a locatable place - affords (see Burrell 2009). Often, we think about the pedagogy of anthropology in relationship to the classrooms we teach in in the institutions where we work. Research, particularly for anthropologists, is something we do elsewhere, often far away. Multimodal invention, we suggest, has the potential to dissolve the distinction between what we do as fieldwork and what we do in classrooms. Multimodal invention holds the promise of connecting the two - the classroom and the field - more viscerally by allowing for a less encumbered circulation and a more immediate connection between the two. In this formulation an education in anthropology is not solely for those who we work with in institutions but for everyone we interact with as counterparts. If, as Tim Ingold (2014) has persuasively argued, an education in anthropology is about bringing students into the world, how might a multimodal anthropology of invention facilitate a pedagogy of engagement and performativity? This challenge to reimagine pedagogy doubles as a challenge to rethink what we imagine the outcomes of our research engagements with others to be in terms of form, circulation, and their correspondences (See Dattatreyan, 2018).

\section{Inventive forms: beyond representation}

It seems clear that experimenting with non-textual modalities creates not only the potentiality for a reimagining of ethnography as collaborative but also generates new forms and contents, as well as new correspondences between them (Vidali 2016; Chio 2017). It is perhaps in relation to multimodality's rupture with the hegemony of written text that the break with representation announced above can be best assessed. The collaborative, experimental and inventive deployment of a range of audio/visual, multimedia and performative strategies displaces both fieldwork dynamics and their "outcomes". As the articles included in this special issue make clear, multimodal inventions are not constructed around a pre-existing 
"thing", "idea" or "practice" to be represented. Rather, they enact encounters in which the unexpected, the unforeseen, the otherwise may be co-produced.

Contemporary Indigenous aesthetics offers a key point of reference here. In their introduction to a recent edited collection, Jennifer L. Biddle and Tess Lea repurpose the term "hyperrealism" to refer to works that "do not aim to re-create the illusion of a reality available elsewhere... Rather, this is art at work to make the real more real, when the real is itself what is at risk, at stake: namely, Indigenous history, language, presence, silenced, denied, ignored." (2018: 6). Biddle and Lea show how experimental engagements with artifice and digital media have provided new ways of asserting Indigenous ways of being away from 'tired paradigms of 'authentic,' 'native,' or 'traditional'” (2018: 5). A prime example are the improvisational, inventive films by Karrabing Collective, such as When Dogs Talked or Wutharr: Saltwater Dreams (see Lea and Povinelli 2018). Hailing from Australia's Northern Territory, but rejecting a purely territorial or lineage adscription, their films stage the condition of Indigenous lifeworlds under contemporary settler colonialism. They don't document it, or simply fictionalize it. Rather, they enact and collectively improvise truthful stories related being Indigenous today - however disorienting they may appear to the noninitiated.

Relatedly, William Lempert (2018) has written about a wave of Indigenous projects that go beyond reclaiming "visual sovereignty" (Dowell 2012) and also exercise "temporal sovereignty" (Rifkin 2017) by invoking Indigenous futures. This constitutes an important step towards a break with "the explicit and implicit ways in which Indigenous people continue to be representationally confined to imagined pasts" (Lempert 2018: 176). Geronimo Inutiq's remix of the Igloolik Isuma Video Archive in his ARCTICNOISE installation (see Hennessy et al. 2018) or Skawennati's reappropriation of Canadian colonial history in the Second Lifebased TimeTraveller ${ }^{\mathrm{TM}}$ would be examples of the use of digital multimodality not as an end unto itself, but because of its "capacity to collectively imagine and creatively communicate stories that matter for the actualization of Indigenous futures" (Lampert 2018: 176). The political significance of these platforms for "imagining otherwise" has been underlined by Turtle Mountain Chippewa scholar Danika Medak-Saltzman:

Indigenous futurisms, like Afrofuturisms and other similar movements, provide authors, readers, filmmakers, audiences, and our communities with opportunities to explore beyond what is and what has been and moves us toward imagining, creating, and manifesting a variety of possibilities that better represent our understandings of, 
our place in, and our responsibilities to this world and to those yet to come... Such futurist work, whether dystopic, utopic, or somewhere in between, serves to counter persistent settler colonial fantasies of Native disappearance. (2017: 143)

Another inspirational example of the politics of multimodality and invention is the work of our Goldsmiths' colleagues Forensic Architecture, a research center that provides counterevidence exposing state and corporate violence. Forensic Architecture uses digital platforms to gather different kinds of traces (such as amateur videos, satellite images, sound recordings or testimonies) and assemble them into multimodal "cases" that challenge official accounts and (re)open the possibility of justice for the victims. They have, for instance, modelled the secret Saydnaya Prison in Syria using survivors' sonic memories, or used images of building ruins to reconstruct covert drone attacks in Pakistan, Gaza, and Yemen. Their investigations disseminated online, taught at university, shown in exhibitions, discussed in legal forums have reinvented what evidence looks like and, more importantly, the relationship between evidence and its material basis. Their work has shown how evidence is not to be found in an image, a sound or a bullet hole, but rather in a particular relationship between media, publics and forums (Weizman, 2017). Remarkably, their novel aesthetics of evidence - where reconstructing "what happened" in a particular instance takes the form of a performative, inventive approach that (re)creates the very relations it intends to portray - has succeeded across the academic, artistic and legal domains.

These new forms and contents offer a challenging, exciting, and yet, in some ways, perilous way forward. A website such as Matsutake Worlds Live, hosted by UCSC and developed by Anna Tsing's students in California and Denmark as a web accompaniment her book The Mushroom at the End of the World (2015), provides an illustrative example. On the one hand, the website offers a means for those who live with mushrooms across the world to contribute short videos of their experiences with them. The website parasitically uses the smartphone and the web as a device by which to iteratively collect and assemble multiple, fragmented understandings of human/mushroom relations. Short videos of markets where mushrooms are sold and forests where they are picked are embedded as pins on a world map. The user can click on one pin to zoom into a specific place, Lapland, Finland for instance, and watch a short video about some aspect of Matsutake mushrooms' symbiotic relationship with humans. These short videos allow us to visualize life with mushrooms across sociohistorical contexts, to virtually map distinction and commonality. The multiplicity of videos creates a multivocal and non-linear engagement for the user. The website, therefore, creates 
new relations between users and producers. On the other hand, the website (as many of our students pointed out when we have taught multimodal approaches to anthropology) often fails. Some links don't work. Nor does there seems to be a curatorial continuity to the project.

It seems evident that in experimenting with new approaches to fashioning ethnographic artefacts that there still work to be done. After all, in making iterative, novel and digitally embedded work we are setting forth into unchartered territory that might bring with it new affordances and complications. As Jenny Chio (2017) rightly argues, while we have the legacy of a coherent review structure for the dissemination of "conventional" anthropological text, we still are in the early stages of creating viable frameworks for multimodal artefacts to be recognized in the discipline, and, for that matter, by other publics. This is certainly the case when it comes to non-textual forms and tenure in the U.S. system and REF in the U.K. system (the accountability structures and academes we know well). In both, a lack of systematicity around how to assess the scholarly contribution and impact of non-textual submissions results in situations where non-textual forms (the website, the film, the photo exhibition, etc.) are made invisible or, if included, become ancillary. Dissemination of these forms, then, are secondary and fugitive. They have the potential to become either the secret epistemological projects that we do on top of what we do to produce ourselves as legible scholars or the thing that we exhaustively spend our time with, to the detriment of our careers. What do the possibilities (and ostensible failures) of multimodal inventions in our present moment teach us about an anthropology yet to come?

This question becomes particularly poignant when we consider recent debates concerning Open Access (OA) publishing that resulted soon after the rather spectacular implosion of HAU: Journal of Ethnographic Theory. OA proponents argue for an infrastructure that would abolish paywalls, thereby making academic knowledge (in textual form) freely accessible to all. The underlying premise behind OA is that access to expert knowledge produces, on its own, an inclusive possibility - a means to disseminate our research to publics who don't have university privileges to access scholarly articles. While both of us are fully on board with removing economic barriers to accessing academic texts, we're also aware that paywalls are not the only walls that need to be demolished. Anand Pandian, writing about the Hau debacle, has explicitly named them:

Walls that shield those securely employed and exalted in anthropology from the acute concerns of those in more precarious positions. Walls that credit the field's white forefathers with its most essential lessons, while relegating others to the status of 
native informants, loyal wives, helpful assistants, or grateful descendants. Walls that distinguish properly deferential and manifestly scholarly writing from forms of expression deemed too intimate, too vulnerable, too personal, too conversational, too passionate to count as serious scholarship. Walls that celebrate the glories of the master's house. Walls that extol good theories at the expense of good stories. (2018)

We would, of course, add to Pandian's list that these walls also keep out forms that don't conform to the text as scholarship paradigm. In any case, we have certainly encountered some of these walls in our academic trajectories; indeed, it was (ironically, it would turn out) the desire to push the boundaries of what counts as (British Social) Anthropology - both in form and in theoretical trajectory - that initially triggered this edited collection. A mutual acquaintance invited us to consider submitting a special issue proposal to Hau on the back of an informal conversation on the relationship between visual anthropology and theoretical innovation during the 2017 Royal Anthropological Institute's Ethnographic Film Festival, where Isaac had organised a workshop on the politics and aesthetics of ethnofiction entitled "Reclaiming Fiction". Hau, a journal committed to a very specific genealogy of the discipline ${ }^{\mathrm{ii}}$, was a rather unlikely venue to publish our take on multimodal anthropology, but that made the idea all the more attractive: the journal's combination of open access, theoretical ambition and increasing prestige offered a visibility that admittedly seduced us. When news of the excesses of the journal's Editor in Chief first became public our proposal for a "special section" had already been submitted and approved. We, collectively, had just submitted our introductory essay and articles. We discussed the situation with our contributors and collectively decided to withdraw our work from $\mathrm{Hau}$. ${ }^{\text {iii }}$

We are very happy to have found a home at American Anthropologist for this collection. In hindsight, which is of course perfectly clear as the saying goes, it seems rather strange we would have thought of anywhere else but American Anthropologist given their recent commitment to multimodal scholarship and their willingness to push the envelope on what counts as relevant anthropological theory and form. Our editors have been enthusiastic and have engaged with our contributions, encouraging us to include more non-textual content to go along with our theoretical propositions as well as to think through and articulate the limits of invention in the multimodal even as we propose its possibilities (which our reviewers also reiterated). It is in the spirit of this inclusive, engaged, and productive generous conversation that we offer you this essay and the articles included our collection. 
All of these essays, we argue, suggest a different way in for us to think about the political salience of ethnography and its capacity to create a more engaged scholarship. If, as Stephane Hessel (2011) argued, "to resist is to create[;] to create is to resist", what new opportunities for resistance does multimodal invention offer? What are the political potentialities of an anthropology that aspires to become a "vehicle" or a "host" for the ideas, desires and affects of non-anticipated interlocutors? The contributions included in this collection engage the multimodal in order to create a new political horizon for the discipline one which is about enacting new conditions of possibility, of thought, of being together (Dattatreyan and Shankar 2016). Such a rewiring of the anthropological project signals a move away from critique, debunking, demystifying, etc. and places co-creation and invention as its central axiom. 


\section{REFERENCES}

Biddle, Jennifer L., and Tess Lea. 2018. "Hyperrealism and Other Indigenous Forms of 'Faking It with the Truth."' Visual Anthropology Review 34 (1): 5-14. https://doi.org/10.1111/var.12148.

Burrell, Jenna. 2009. "The Field Site as a Network: A Strategy for Locating Ethnographic Research.” Field Methods 21 (2): 181-99. https://doi.org/10.1177/1525822X08329699.

Chio, Jenny. 2017. "Guiding Lines." Cultural Anthropology website, May 2, 2017. https://culanth.org/fieldsights/1118-guiding-lines

Collins, Samuel Gerald, Matthew Durington, and Harjant Gill. 2017. "Multimodality: An Invitation.” American Anthropologist 119 (1): 142-46. https://doi.org/10.1111/aman.12826.

Conquergood, Dwight. 1998. Performance Studies. Interventions and Radical Research. TDR 46 (2): $145-156$.

Cox, Rupert, Andrew Irving, and Christopher Wright, eds. 2016. Beyond Text?: Critical Practices and Sensory Anthropology. Manchester: Manchester University Press.

Dattatreyan, Ethiraj Gabriel, and Arjun I. Shankar. 2016. "Multimodal Ethnography and the Possibilities for Engaged Anthropology." Anthropology News 57 (10): e76-80. https://doi.org/10.1111/AN.198.

Dattatreyan, Ethiraj Gabriel. 2018. Critical hip hop cinema: Racial logics and ethnographic ciphas in Delhi. Widescreen 7.1. http://widescreenjournal.org/index.php/journal/article/view/119

De la Cadena, Marisol. 2015. Earth Beings: Ecologies of Practice across Andean Worlds. Durham: Duke University Press Books.

Deleuze, Gilles. 1997. Cinema 2: The Time Image. London: Continuum International Publishing Group Ltd.

Estalella, Adolfo, and Tomas Sanchez-Criado, eds. 2018. Experimental Collaborations: Ethnography through Fieldwork Devices. New York: Berghahn Books.

Favero, Paolo S. H., and Eva Theunissen. 2018. "With the Smartphone as Field Assistant: Designing, Making, and Testing EthnoAlly, a Multimodal Tool for Conducting Serendipitous Ethnography in a Multisensory World.” American Anthropologist website, February 21.

Harney, Stefano, and Fred Moten. 2013. The Undercommons. Wivenhoe: Minor Compositions. 
Hessel, Stéphane. 2011. Time for Outrage: Indignez-Vous! New York: Twelve.

Holmes, Douglas R., and George E. Marcus. 2008. "Collaboration Today and the ReImagination of the Classic Scene of Fieldwork Encounter." Collaborative Anthropologies 1 (1): 81-101.

Ingold, Tim. 2014. “That's Enough about Ethnography!” HAU: Journal of Ethnographic Theory 4 (1): 383-95.

Jackson Jr., John L. 2013. Thin Description: Ethnography and the African Hebrew Israelites of Jerusalem. Cambridge, Massachusetts: Harvard University Press.

Johnson, E. Patrick. 2011. Sweet Tea: Black Gay Men of the South. 2 edition. Chapel Hill: University North Carolina Press.

Lea, Tess, and Elizabeth A. Povinelli. 2018. "Karrabing: An Essay in Keywords." Visual Anthropology Review 34 (1): 36-46. https://doi.org/10.1111/var.12151.

Lempert, William. 2018. "Indigenous Media Futures: An Introduction.” Cultural Anthropology 33 (2): 173-79. https://doi.org/10.14506/ca33.2.01.

Lury, Celia, and Nina Wakeford, eds. 2012. Inventive Methods: The Happening of the Social. London; New York: Routledge.

MacDougall, David. 1998. Transcultural Cinema. Princeton, N.J.: Princeton University Press.

Marcus, George E. 2008. “The End(s) of Ethnography: Social/Cultural Anthropology's Signature Form of Producing Knowledge in Transition." Cultural Anthropology 23 (1): $1-14$.

Marcus, George E. 2010. "Contemporary Fieldwork Aesthetics in Art and Anthropology: Experiments in Collaboration and Intervention." Visual Anthropology, 23(4), 263-277. https://doi.org/10.1080/08949468.2010.484988

Marrero-Guillamón, Isaac. 2018a. "The Politics and Aesthetics of Non-Representation: ReImagining Ethnographic Cinema with Apichatpong Weerasethakul." Antípoda. Revista de Antropología y Arqueología, no. 33 (October): 13-32. https://doi.org/10.7440/antipoda33.2018.02.

Marrero-Guillamón, Isaac. 2018b. "Making Fieldwork Public: Repurposing Ethnography as a Hosting Platform in Hackney Wick, London.” In Experimental Collaborations: Ethnography through Fieldwork Devices, edited by Adolfo Estalella and Tomas Sanchez-Criado, 179-200. New York: Berghahn Books.

Marres, Noortje, Michael Guggenheim, and Alex Wilkie, eds. 2018. Inventing the Social. Manchester: Mattering Press. 
Mazzarella, William. 2004. "Culture, Globalization, Mediation.” Annual Review of Anthropology (33): 345-367.

Medak-Saltzman, Danika. 2017. "Coming to You from the Indigenous Future: Native Women, Speculative Film Shorts, and the Art of the Possible." Studies in American Indian Literatures 29 (1): 139-71. https://doi.org/10.5250/studamerindilite.29.1.0139.

Pandian, Anand. “Open Access, Open Minds.” Dispatches, Cultural Anthropology website, June 15, 2018. https://culanth.org/fieldsights/1455-open-access-open-minds

Pink, Sarah. 2009. Doing Sensory Ethnography. Los Angeles; London: SAGE.

Pink, Sarah. 2011. "Multimodality, Multisensoriality and Ethnographic Knowing: Social Semiotics and the Phenomenology of Perception." Qualitative Research 11 (3): 26176. https://doi.org/10.1177/1468794111399835.

Savransky, Martin. 2016. The Adventure of Relevance: An Ethics of Social Inquiry. London: Palgrave Macmillan.

Savransky, Martin. 2017. “A Decolonial Imagination: Sociology, Anthropology and the Politics of Reality." Sociology 51 (1): 11-26. https://doi.org/10.1177/0038038516656983.

Stoller, Paul. 1997. Sensuous Scholarship. Philadelphia: University of Pennsylvania Press. Taylor, Lucien. 1996. “Iconophobia.” Transition, no. 69 (January): 64-88. https://doi.org/10.2307/2935240.

Tsing, Anna Lowenhaupt. 2015. The Mushroom at the End of the World: On the Possibility of Life in Capitalist Ruins. Princeton: Princeton University Press.

Visweswaran, Kamala. 2010. Un/Common Cultures: Racism and the Rearticulation of Cultural Difference. Durham, NC: Duke University Press Books.

Vidali, Debra S. 2016. "Multisensorial Anthropology: A Retrofit Cracking Open of the Field.” American Anthropologist, 118: 395-400. doi:10.1111/aman.12595

Viveiros de Castro, Eduardo. 2014. Cannibal Metaphysics. Minneapolis, MN: Univocal Publishing.

Wagner, Roy. 1981. The Invention of Culture. Chicago and London: University of Chicago Press.

Weizman, Eyal. 2017. Forensic Architecture: Violence at the Threshold of Detectability. 1 edition. Brooklyn, NY: Zone Books - MIT.

West, Paige. "Introduction: From Reciprocity to Relationality." Hot Spots, Cultural Anthropologywebsite, September 26, 2018. https://culanth.org/fieldsights/1526introduction-from-reciprocity-to-relationality 


\begin{abstract}
${ }^{\text {i }}$ See Marrero-Guillamón (2018a) for an engagement with this question in the (paraethnographic) cinema of Apichatpong Weerasethakul.

ii Paige West (2018) has written eloquently about Hau's role in the reintroduction and reproduction of the anthropological canon from the 1950s-1970s. She writes: "Early on, HAU's editors argued that they were attempting to return to a kind of anthropology that centered theory derived from ethnography, and yet what they actually did was to privilege certain genealogies of knowledge that predated the groundbreaking, field-changing feminist, Indigenous, Black, and LGBTQI inroads into the academic establishment from the mid-1970s to the present."

iii We had initially submitted a proposal to the journal's open call for "special issues". This was rejected by Hau in July 2017, although we were invited to consider preparing a shorter "special section". We accepted and first versions of this introduction and the accompanying articles were submitted in March 2018. Meanwhile, in the Winter 2017 issue of Hau, the journal had announced that they were abandoning its blanket open access policy in favour of a more limited model developed in collaboration the University of Chicago Press (UCP). This was disappointing news to us, but we carried on. Maybe it was the inertia of the process; maybe it was our ambition to enter the Hau ring. In any case, we hadn't heard anything about our "special section" when, in June, the scandal broke out, and we collectively decided to pull out. We did so before an alternative had been worked out, but the task of finding a new venue for our work was easier than expected. Of those we approached, American Anthropologist were, by far, the most interested and supportive. Our contributors were all keen to complete the move, and by late July 2018 the review process at AA had already started.
\end{abstract}

\title{
Acknowledgements
}

We would like to thank our reviewers for their careful attention to this essay and the articles included in our collection. We would also like to thank the editorial team at American Anthropologist -Deborah Thomas, Matthew Durington, Harjant Gill, and Samuel Collins. They have been incredibly supportive and incisive in their feedback throughout the review process and for that we are grateful. Isaac would like to thank Gabriel for being his thought partner throughout this process. Gabriel would like to thank his friends at Camra and in the greater Philadelphia area for inspiring his commitments to multimodal scholarship, Isaac for engaging so generously and thoughtfully as we formulated our arguments together, and all the contributing authors for their careful and insightful articles that, we believe, place multimodal anthropology on new terrain. 